\title{
ALFABETIZAÇÃO CIENTÍFICA E TECNOLÓGICA NA FORMAÇÃO DO CIDADÃO
}

\author{
Gildete Elias Dutra ${ }^{1}$ \\ Eniz Conceição Oliveira² \\ José Cláudio Del Pino ${ }^{3}$
}

\begin{abstract}
Resumo: No presente artigo aborda-se uma revisão bibliográfica acerca da alfabetização científica e tecnológica na formação do cidadão. Sendo assim, discutem-se os diferentes significados e funçóes que se têm atribuído à educação científica e tecnológica, elencando os referenciais para reflexão do papel dessa educação, por meio do ensino de ciências como conhecimento importante no desenvolvimento da cidadania. Reflete-se, ainda, sobre a formaçáo inicial e continuada do professor, por entender que este tem o papel fundamental que lhe é imposto pela sociedade contemporânea.
\end{abstract}

Palavras-chave: Ensino de Ciências. Formação. Cidadão. Alfabetização Científica e Tecnológica.

\section{SCIENTIFIC AND TECHNOLOGICAL LITERACY FOR THE EDUCATION OF THE CITIZEN}

\begin{abstract}
The present article is a bibliographical revision on Scientific and Technological Literacy for the education of the citizen. So, it brings some different meanings and functions which have been attributed to scientific and technological studies. The bibliography used as a base for the Teaching of Sciences for the knowledge in the development of citizenship is also mentioned. The text also reflects on the initial and continued formation of the teacher of Sciences and his fundamental role which is imposed by contemporary society.
\end{abstract}

Keywords: Teaching of Sciences. Education. Citizen. Scientific and Technological Literacy.

1 Graduada em Geografia (UEMA). Especialista em Metodologia do Ensino de Geografia (UEMA). Especialista em Políticas Educação do Ensino Superior (FEST). Mestranda do Curso de Pós-Graduação em Ensino da UNIVATES. Professora. E-mail: gildetedutra@hotmail.com

2 Graduada em Química (UFRGS). Mestra em Química (UFRGS). Doutora em Química (UFRGS). Professora do Curso de Pós-Graduação em Ensino da UNINATES. E-mail: eniz@univates.br

3 Graduado em Química (UCRS). Mestre em Ciências Biológicas-Bioquímica (UFRGS) Doutor em Engenharia de Biomassa (UFRGS). Professor do Curso de Pós-Graduação em Ensino da UNIVATES. E-mail: jose.pino@univates.br 


\section{INTRODUÇÃO}

$\mathrm{Na}$ contemporaneidade tem sido uma constância as discussões relacionadas à evolução científica e seu reflexo na educação, nesse aspecto, são vários entendimentos que se tem de alfabetização científica e tecnológica. Compreender seu significado é encontrar possibilidades de relacionar a ciência e a tecnologia com todas as áreas do conhecimento humano, consequentemente a formação da cidadania na sua plenitude.

Considerando que vivemos em um mundo influenciado pelas ciências e tecnologias, importa-nos associar alfabetização científica ao processo de aquisição de estruturas conceituais que explicitam princípios científicos básicos, a fim de explicar a importância dessa denominação na formação do cidadão exigido por esta nova sociedade que toma forma gradativamente.

Segundo Santos e Mortimer (2002, p.1), "as sociedades modernas passaram a confiar na ciência e na tecnologia como se confia em uma divindade". A partir desse processo de valorização da ciência e da tecnologia surge o cientificismo e com isso, a ideia de que a ciência pode resolver todos os problemas da humanidade.

\section{O ENSINO DE CIÊNCIAS NO DESENVOLVIMENTO DO CIDADÃO}

O ensino de ciências tem sofrido inúmeras propostas de inovação. Essas propostas têm o objetivo de melhorar a formação científica do cidadão, tendo em vista às circunstâncias históricas e culturais da sociedade, e assim, situar a ciência e o seu ensino no tempo e no espaço.

A emergência desse conceito busca superar os problemas vividos pela utilização do conhecimento científico que privilegia decisões particularistas e tecnocratas e fazer com que o ensino da ciência seja mais vinculado à realidade do educando, permitindo sua maior participação na sociedade frente aos avanços científicos e tecnológicos (CHASSOT, 2006).

O conceito de alfabetização científica, no campo da formação do cidadão, é associado ao conceito do saber funcional, tendo em vista que o saber técnico está relacionado à resolução de problemas concretos. Hazen e Trefil (2005, p. 12), assim definem Alfabetização Científica:

[...] é ter o conhecimento necessário para entender os debates públicos sobre as questões de ciência e tecnologia [...] O fato é que fazer ciência é inteiramente diferente de usar ciência. E a alfabetização científica refere-se somente ao uso das ciências.

Contudo, ser alfabetizado cientificamente não significa dominar todo o conhecimento científico, pois nem os cientistas dominam todas as áreas. Ser alfabetizado em ciências significa ter o conhecimento necessário para avaliar os avanços das ciências e das tecnologias e suas implicações na sociedade.

[...] você não precisa se tornar um cientista para compreender o que está acontecendo [...]. Não é condição obrigatória saber estabelecer a sequência 
de uma molécula de DNA para entender notícias de jornais a respeito do assunto, assim como não é preciso saber projetar um avião para fazer uma viagem aérea, nem tornar-se um engenheiro projetista para se deslocar numa bicicleta (COSTA, 2006, p. 73).

No entanto, é relevante acompanhar as mudanças do mundo científico, saber o que está sendo desenvolvido para conhecer suas consequências positivas e negativas e assim, fazer as possíveis intervenções, bem como conhecer também o impacto das ciências e das tecnologias na sociedade e a influência da sociedade no desenvolvimento científico e tecnológico.

Definimos a alfabetização científica como sendo a apreensão dos princípios científicos de bases essenciais para que o indivíduo possa compreender, interpretar e interferir adequadamente em discussões, processos e situações de natureza técnico-científica ou relacionados ao uso da ciência e da tecnologia (LACERDA, 1997, p. 8).

Entendemos que a alfabetização científica representa um conjunto de conhecimentos científicos e tecnológicos que facilitariam aos homens e mulheres fazer uma leitura do mundo onde vivem, para assim compreendê-lo e transformá-lo, pois para Santos (2007, p. 475), "não ficam restritas às academias, universidades e/ ou mesmo nos laboratórios. Os conteúdos [...] tomaram os meios de comunicação, abrindo espaços para divulgação de novas e velhas descobertas científicas em diversas áreas do saber".

Nesse aspecto, alfabetizar o cidadão em ciências e tecnologias é uma necessidade do mundo contemporâneo, sendo assim, ensino de ciências, por meio das dimensões ciência, tecnologia e sociedade, pode contribuir para o desenvolvimento da cidadania. Caldeiras e Bastos (2002, p. 209), explicam que o ensino de ciências deve:

[...] ensinar novas maneiras de interpretar e analisar o mundo natural e social, tendo em vista uma formação para a cidadania informada, atuante, responsável e solidária; uma formação que contemple, por exemplo, a valorização da vida, o envolvimento com as questões ambientais, à prevenção de doenças e uma luta por melhores condições de existência para todos.

É notório o descompasso entre as práticas escolares e a dinamicidade das transformações espaciais e temporais do mundo atual. Os avanços científicos e tecnológicos, a reestruturação produtiva, as mudanças no processo de trabalho e a intensificação dos meios de comunicação são alguns exemplos de transformações que vêm ocorrendo na sociedade (LIBÂNEO, 2007). Essas transformações ocorrem de maneira inédita, a uma velocidade sem precedentes na história, e em direção a um futuro de contornos inimagináveis.

Nesse contexto, cabe a escola a função de acompanhar e refletir sobre o advento de uma sociedade eminentemente tecnológica, na qual as aplicações práticas do trabalho científico estarão cada vez mais inseridas no cotidiano do cidadão. 
Conforme afirma Lacerda (1997), tal sociedade deve estar intrinsecamente relacionada ao advento das novas tecnologias, tendo sua dinâmica de funcionamento baseada principalmente em noções de globalização, polivalência, eficiência, autonomia e descentralização. Estamos, de fato, num período de revolução global, o maior já registrado na história.

Nesse sentido, a ciência e a tecnologia estão presentes em nosso cotidiano, em nossa cultura, em nosso consciente e em nosso inconsciente, assim, contribuem para uma grande transformação na maneira como vivemos, trabalhamos e pensamos.

Nesta perspectiva de ideias, devemos reconhecer o papel estratégico e crucial de um conhecimento de base em ciências e tecnologias na formação do cidadão da sociedade emergente.

Trata-se da instrumentação do indivíduo com conhecimentos científicos válidos e significativos tanto do ponto de vista social quanto do ponto de vista individual, sem os quais o próprio exercício da cidadania ficaria comprometido na medida em que ele depende, entre outros aspectos, da intervenção profissional e da autossatisfação do indivíduo como detentor de conhecimentos técnicos que lhe são pertinentes (LACERDA, 1997, p. 9)

O envolvimento com questões como cidadania, tecnologias, prática escolar, linguagem, cultura, história, saberes populares e escolares, religião, dentre outras, possibilita-nos fazer a inter-relação de saberes socialmente construídos e elaborados, com os quais estão sendo construídos constantemente pelas ciências na contemporaneidade (CHASSOT, 2006).

Para Morin (2004, p. 10), "[...] nesse século de tantas mudanças e concepções, a educação, é vista muito mais do que um veículo de transmissão de conteúdos”. O desafio maior, para esse autor, seria como fazer para que os conteúdos escolares contribuam para a construção de indivíduo mais humano; que saiba transformar os conteúdos em conhecimentos tanto para o seu benefício quanto para a sociedade.

Para fazer ciência, é necessário que tenha um ponto de partida, e de preferência que esse ponto de partida seja conhecido e interessante para por todos os envolvidos no processo (CHASSOT, 2008).

Nos dias atuais é difícil conceber propostas de ensino de ciências sem os aspectos sociais e pessoais dos estudantes, ou seja, no processo ensino aprendizagem é importante considerar os saberes populares, desenvolvendo assim, uma alfabetização científica a partir do mundo que é conhecido pelos alunos e cidadãos. Considerando esse ensino a partir de novas perspectivas, surge a necessidade de reavaliar o ensino de ciências, atualmente desenvolvido na escola. Transcender este modelo de ensino é uma exigência para a escola na contemporaneidade.

Segundo Freire (1996), tanto o aluno quanto o professor são protagonistas no processo ensino aprendizagem. No entanto, é o professor o responsável para que a aprendizagem se dê de forma significativa, devendo ser o motivador e mediador no processo de alfabetização científica. Assim, a formação inicial e continuada do 
professor é fundamental para que o mesmo possa dar conta do papel que lhe é imposto pela sociedade.

Nessa direção, exige-se desse novo professor uma visão holística em relação tanto ao ensino como também a aprendizagem. Para isso, é preciso que este busque na formação permanente a compreensão dos princípios e saberes necessários à alfabetização científica e tecnológica do cidadão pleno.

Para Pimenta (1999), saber específico seria aquele que os professores disponibilizam para que seus discentes construam seu aprendizado. $O$ saber pedagógico, por sua vez, é o conhecimento que subsidia a ação de ensinar. E a experiência seria o conhecimento acumulado durante toda a sua vida, na relação consigo mesmo e com o outro, sendo a formação continuada responsável pela sua prática.

Nessa perspectiva, é imprescindível a formação de professores voltada à alfabetização científica e tecnológica, bem como inserir a pesquisa nesse processo de formação. O professor pesquisador é capaz de ultrapassar limites impostos pela concepção da escola tradicional. O professor alfabetizado cientificamente e tecnologicamente é capaz de proporcionar o desenvolvimento desta alfabetização na sala de aula, e contribuir na construção de novos valores que venham ao encontro das necessidades da sociedade contemporânea e da formação do cidadão na sua plenitude.

\section{CONSIDERAÇÓES FINAIS}

Entendemos que um indivíduo é considerado alfabetizado cientificamente e tecnologicamente quando é capaz de ter posições autônomas em relação ao mundo contemporâneo, sabendo agir como agente de transformação social, diante dos impactos causados, principalmente, na natureza. Nessa perspectiva, a escola, também, é responsável pela autonomia do indivíduo.

Considerando o dinamismo da sociedade contemporânea, o ensino das ciências e das tecnologias deve ser capaz de fornecer subsídios para que os alunos reflitam sobre problemas do cotidiano e busquem soluções visando o futuro sustentável, ou seja, um ensino pautado no entendimento de mundo, cuja aplicação deste seja o cidadão contemporâneo, além da formação de futuros cientistas.

Quando falamos em cidadania ou em formar cidadão, é necessário entendermos que a cidadania só pode ser exercida plenamente se o cidadão ou cidadã tiver acesso ao conhecimento e não somente às informações. Consequentemente, seu senso crítico perpassa pela leitura do mundo e na intervenção que venha fazer na melhoria pessoal e coletiva. Pois a instrumentalização capacita indivíduos com conceitos e princípios científicos fundamentais para uma participação ativa na sociedade, tanto em nível da compreensão de fenômenos e procedimentos, quanto em nível da facilitação do processo de aquisição de novos conhecimentos.

O embasamento teórico permitiu-nos inferir que os aspectos diferentes de uma mesma temática, delimitada pela crescente inclusão tecnológica em todos 
os setores da sociedade, apontam para um caminho inevitável quando se trata de dotar o cidadão de conhecimentos indispensáveis a uma percepção adequada desta inclusão tecnológica, tais como: causas, impactos, consequências e repercussões.

Nessa direção, os professores precisam estar alinhados com o que é cobrado deles enquanto educadores, munindo-se não somente dos conceitos científicos para que haja a absorção e processamento por parte do aluno, mas também, de uma prática pedagógica que vá ao encontro dos objetivos requeridos em qualquer área, para que culmine a aplicabilidade do que é aprendido. Para tanto, esse professor deve estar em contínua formação, ao mesmo tempo inovando suas metodologias, pois na prática educativa, a alfabetização científica e tecnológica poderá concretizarse de muitas formas e permitir que as pessoas alfabetizadas tomem decisões em situações que envolvam diferentes níveis de complexidade.

Contudo, não podemos esquecer que as atitudes relacionadas com as ciências e as tecnologias devem ser trabalhadas desde os primeiros anos de escolarização a fim de preparar o estudante em relação ao desenvolvimento da sua alfabetização científica e tecnológica para a vida adulta. Por este motivo, a escola deve prever o desenvolvimento de hábitos que propiciem uma formação permanente do cidadão.

\section{REFERÊNCIAS}

CALDEIRAS, A. M. A.; BASTOS, F. Alfabetização Cientifica. In: Vale, J. M. F. at al., (Orgs). Escola Pública e Sociedade. Bauru: Saraiva, 2002.

CHASSOT, A. Alfabetização científica: questões e desafios para a educação. 4 ed. Ijuí: Ed. Unijui 2006.

Fazendo educação em ciências em um curso de Pedagogia com inclusão de saberes populares no currículo. Química Nova na Escola. n. 27. fev,2008.

COSTA, Alice. Ciências e Interação. Curitiba: Positivo, 2006

FREIRE, Paulo. Pedagogia da Autonomia: Saberes necessários à prática educativa. São Paulo: Paz e Terra, 1996.

HAZEN, Robert M.; TREFIL, James. Saber Ciências. São Paulo: Cultura, 2005.

LACERDA, Gilberto. Alfabetização científica e formação profissional. Educação \& Sociedade, ano XVIII, no 60, dezembro/97. Disponível em: http://www.scielo.br/pdf/ esv18n60/v1860a5.pdf >. Acesso em: 28 fev.2017.

LIBÂNEO, José. C. A. A escola que sonhamos é aquela que assegura a toda formação cultural e científica para a vida pessoal, profissional e cidadã. In: COSTA, Maisa V. (org.). A escola do futuro?. Rio de Janeiro: Lamparina, 2007.

MORIN, Edgar. Os sete saberes necessários à educação do futuro. São Paulo. Ed. Cortez, Brasilia, DF: UNESCO, 2004.

PIMENTA, Selma Garrido. Saberes pedagógicos e atividades docentes. Cortez. São Paul, 1999. 
SANTOS, Wildson L. P. dos. Educação científica na perspectiva de letramento como prática social: funções, princípios e desafios - Revista Brasileira de Educação v. 12 n. 36 set./dez. 2007.

SANTOS, Wildson. L. P. dos; MORTIMER, E. F. Uma análise de pressupostos teóricos da abordagem C-T-S (Ciência - Tecnologia - Sociedade) no contexto da educação brasileira. Pesquisa em Educação em Ciências, v.2, n.2, 2005. Disponível em: <http://pt.slideshare.net/ProfessorAdalbertoAzevedo/santos-mortimer-2002>. Acesso em: 01 mar. 2017. 